\title{
NATURAL FACTORS AFFECTING ECO-ARCHITECTURE (DADES OASIS MODEL)
}

\author{
Farida OUZDI ${ }^{1}$
}

\section{Istanbul / Türkiye \\ p. $90-105$}

Received: $29 / 11 / 2021$

Accepted: 08/12/2021

Published: 01/01/2022

This article has been scanned $t$ iThenticat No plagiarism detected

\begin{abstract}
:
Some unfortunate brothers were baptized to feasts and banquets for the public, and during season times Historical sources ndicate that the cults of the Abbasid Caliphs, including the Abbasid aliphate Al-Mahdi, the Mamoun and the Mu 'taad, ranged between six thousand and a thousand dinars a day, while the expenses of the Al-Mutakil kitchen amounted to one thousand dirhams, which is a fairly large budget.

He was also known to identify the Abbasids with public and rivate tables, including the Caliph al-Mansur Al-Rasheed al-Mamoun with a stature favourable to the general public in addition to the state of development that Arab and Islamic society witnessed during the Arab era, in terms of the literature of the gourmet and the pious tools related to the Arab cuisine Result for Tth.
\end{abstract}

Key words: Dades Oasis, Eco-Architecture.

http://dx.doi.org/10.47832/2717-8293.15.7 


\title{
العوامل الطبيعية المؤثرة في العمارة البيئية \\ (واحة دادس أنموذجا)
}

\section{فريدة أزدي 2}

\begin{abstract}
الملخص: ارتبط استقرار الإنسان بالمجالات الواحية، بمدى إمكانية العيش التي يمكن أن يوفره له هذا المجال. فكان الماء هو العامل الأول الذي جذب الإنسان. قام هذا الأخير بتكييف العناصر الأخرى المكونة للطبيعة لصالحه بما يوافقها،

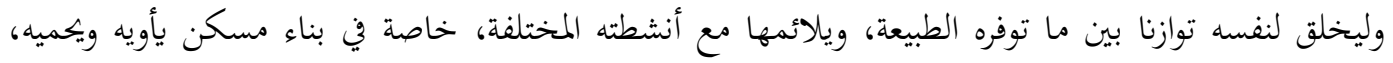

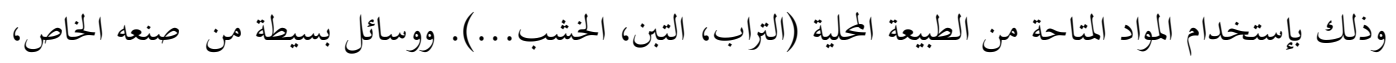
وتقنيات محلية معروفة بالتابوت أو الطابية. هذه العمار المشيدة من طرف الإنسان الواحي تعتبر صديقة للبيئة

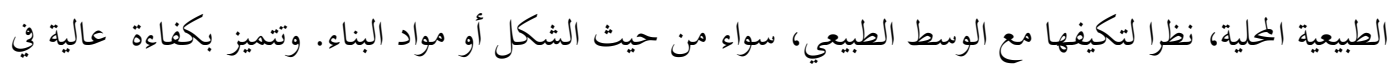

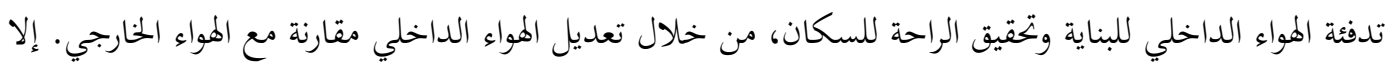

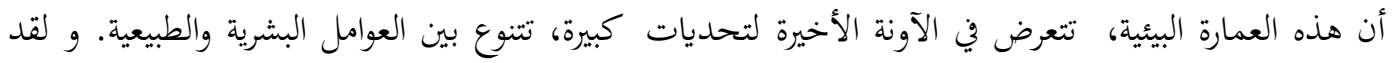

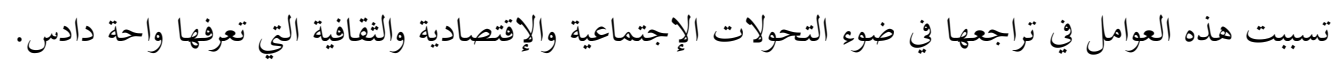
الكلمات المفتاحية: العمارة البيئية، الواحة، العوامل الطبيعية.
\end{abstract}

تعتبر العمارة البيئية من أهم مظاهر تفاعل الإنسان مع البيئة الطبيعية داخل المجال الواحي، وتحدي كل ظروف الحياة

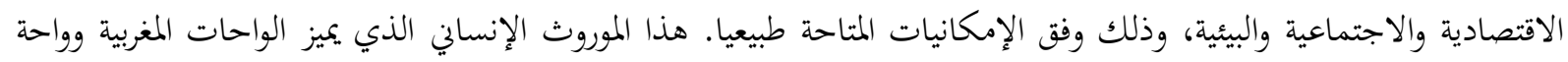

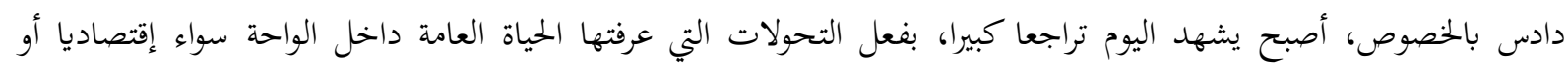
إجتماعيا وثقافيا.

شكلت كل هذه التحولات تحديا أمام استمرارية العمارة البيئية، خاصة بعد الإهمال والتهميش الذي لحقها من طرف الإنسان. ما جعلها عرضة لكل أسباب التدهور الطبيعية والبشرية. وستركز هذه الدراسة على العوامل الطبيعية المؤثرة على العمارة

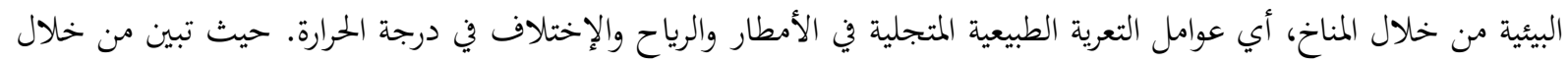
المسح الميداني الدمار الكبير الذي تخلفه هذه الأخيرة على المباني الواحية التقليدية.

تشكل العمارة البيئية أحد أهم المعالم الحضارية بواحة دادس. كما أها الشاهد الأساسي على تاريخ المجتمعات، وثقافتها

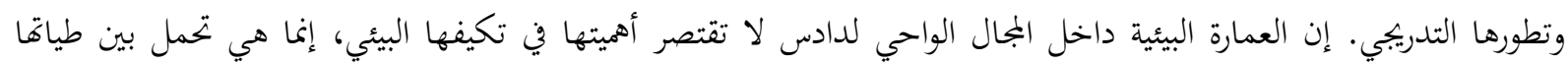

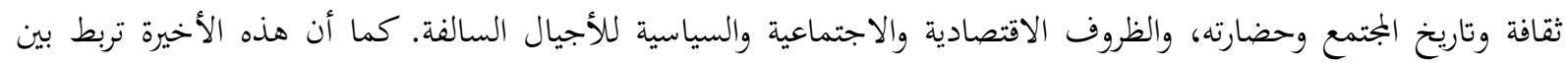

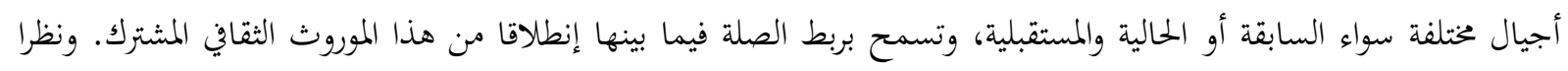


لتطور التحديات الطبيعية والبشرية وعمق تأثيرها على العمارة البيئية بالمجال الواحي مع مرور الزمن، كان من الأهمية بمكان إثارة

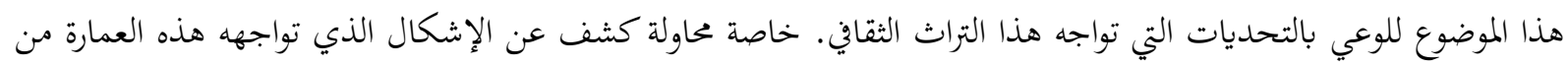

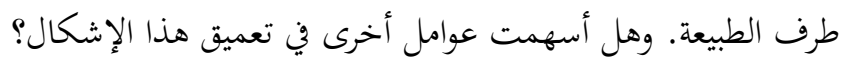

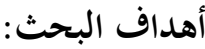

تحدف هذه الدراسة إلى كشف بعض العوامل الطبيعية المؤثرة في العمارة البيئية بواحة دادس الواقعة بالجنوب الشرقي المغربي،

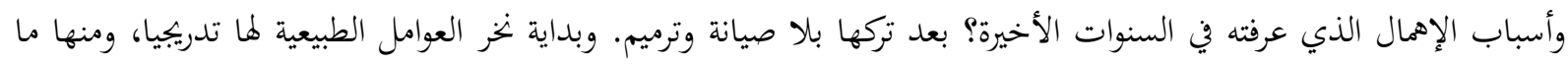

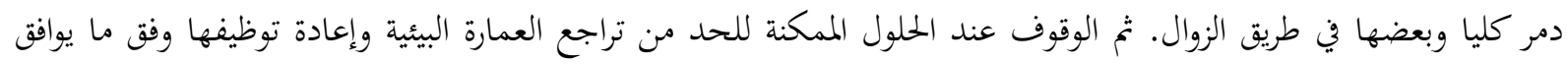
العصر الحديث، وذلك باقتراح بعض التدابير اللممكنة للنهوض بهذا الموروث الحضاري والعمل على استدامتهن.

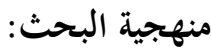

اعتمد في هذه الدراسة على المنهج الوصفي التحليلي، لجمع المعلومات والبيانات المتعلقة بالعمارة البيئية، والوقوف على الملى

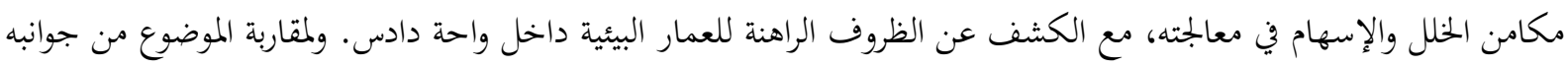

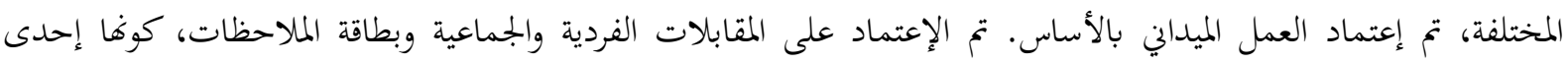

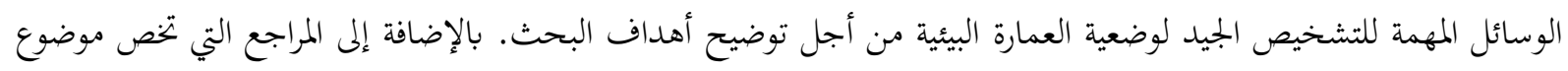

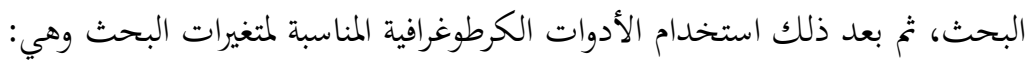

\section{Arc GIS برنامج -}

Google Earth صور -

- الصور الرقمية لمجال الدراسة -

\section{1. - 1 العمارة البيئية بواحة دادس}

يقصد بالعمار البيئية، المباني المتكيفة مع الوسط البيئي الطبيعي. لأها تعتمد على الموارد الطبيعية. فهي لا تأثر على البيئة

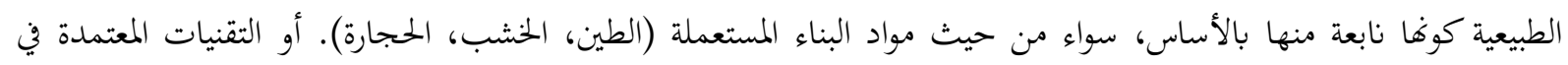

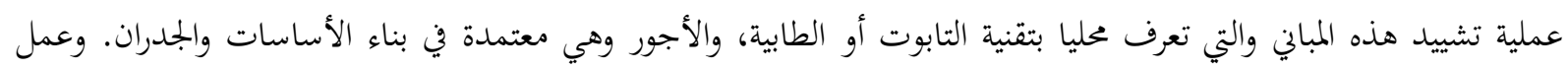

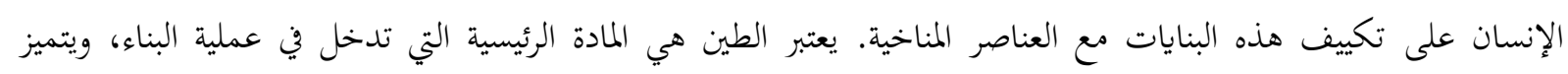

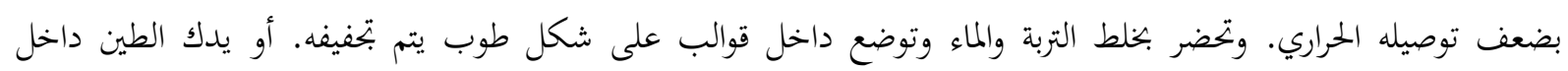

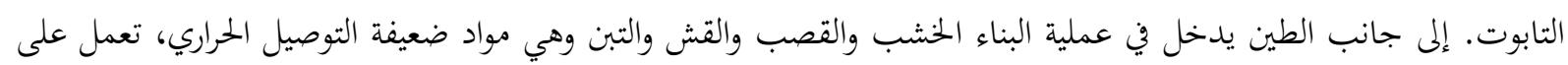
نقل الحرارة بالتباطؤ التدييجي إلى داخل المبنى. وتمثل القصبات والقصور والدور التقليدية هذه العمارة البيئية داخل الواحة.

1.1 موقع واحة دادس

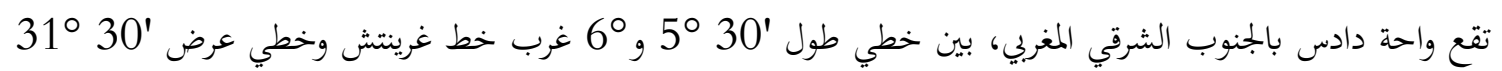

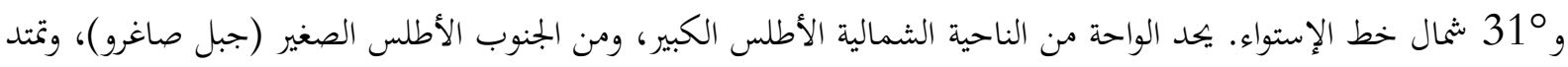
على طول وادي دادس (خريطة رقم 1). 
أسهم الموقع الجغرافي للواحة بخصائصه المناخية، في تبني الإنسان بهذا المجال سلوكات معينة نابعة من العمل الجماعي الذي

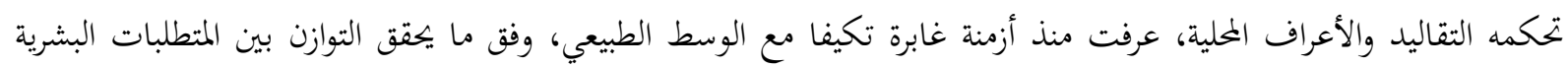

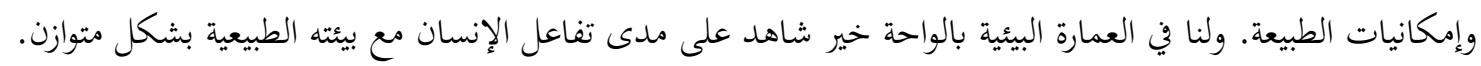

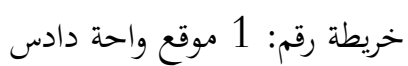

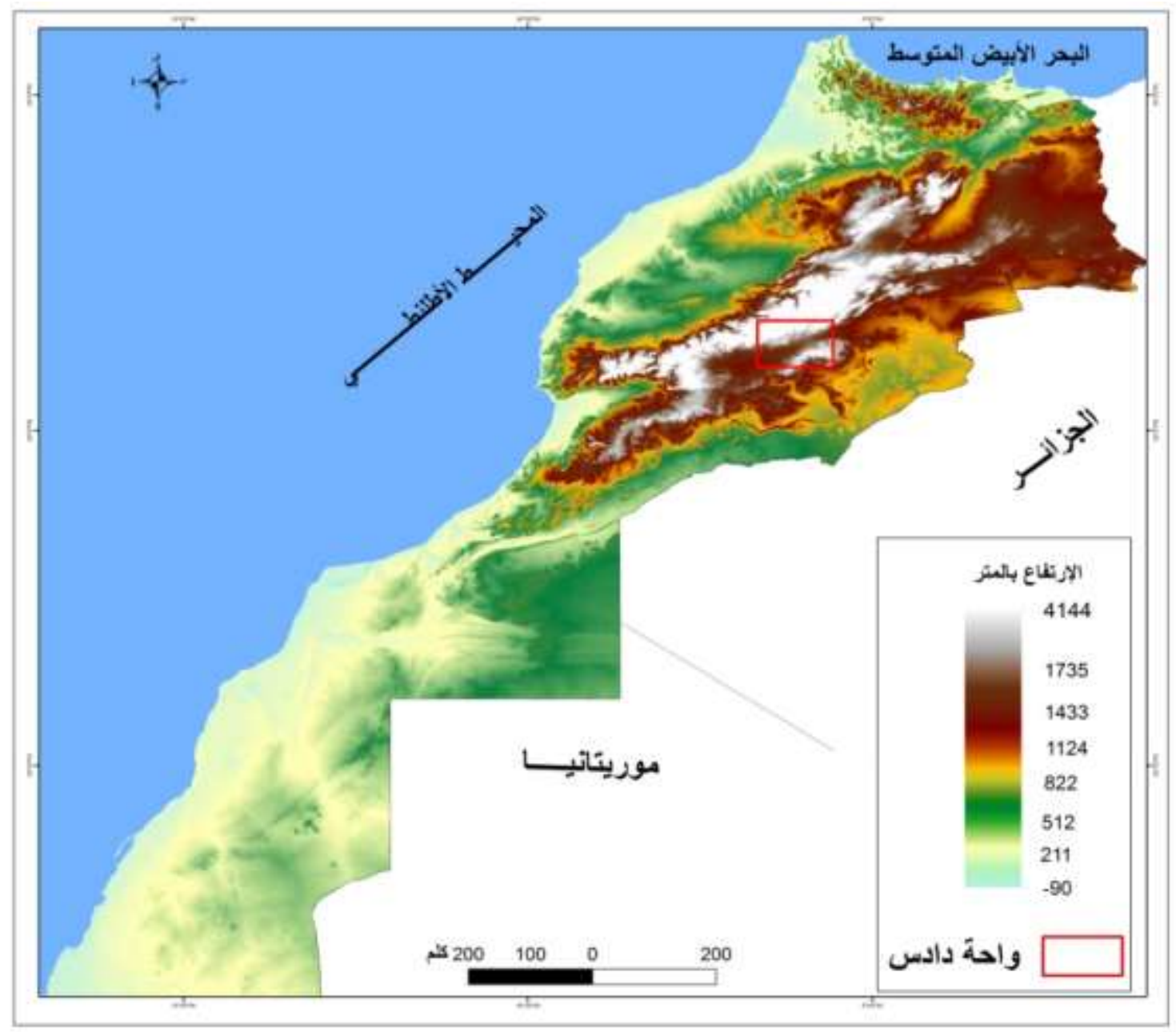

المصدر: الصور الرقمية لواحة دادس

نظرا للموقع الجغرافي للواحة، وانفتاحها في الجنوب على المؤثرات الصحراوية الجافة. ما أضفى عليه المناخ شبه جاف.

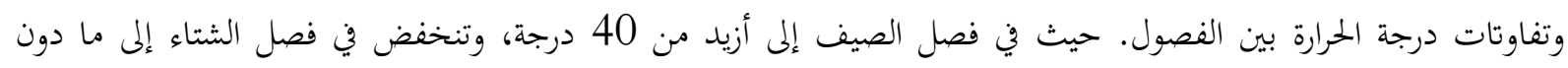

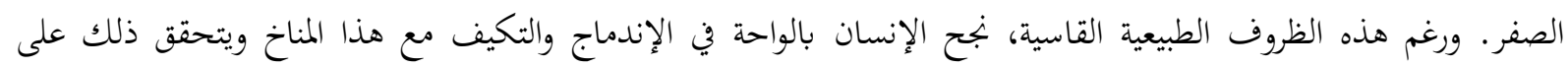
مستوى العمارة البيئة. أنماط العمارة البيئية بالواحة

تشكل المباني التقليدية مركز الإنتماء المشترك لكل الفئات الإجتماعية المشكلة للمجال. وتعتبر هذه المباني من أهم مظاهر

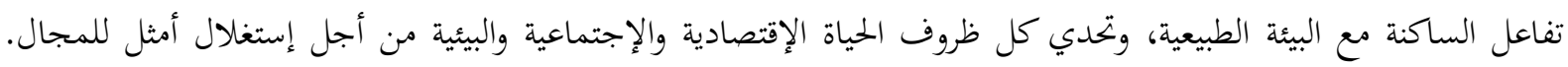
وتتنوع هذه المباني بين القصور؛ كوحدات سكنية أولى جمعت فئات إجتماعية مختلفة والقصبات التي بنيت بعد الإستقلال التدريجي عن القصر ثم الدور التقليدية. 
القصور: تتعدد تعاريف الباحثين لهذا النوع من العمارة البيئية كل من زاويته، فهناك من يعطي القصر أو كم يسمى محليا

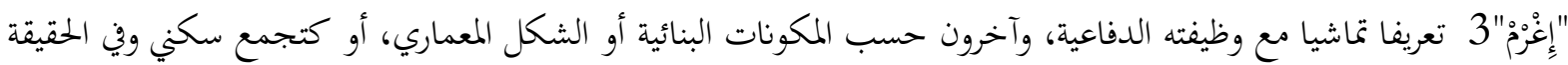

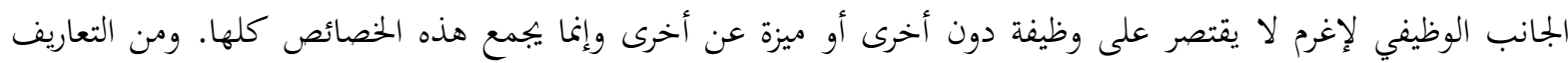

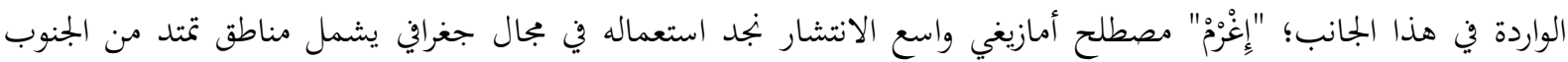
الأطلس الكبير والجنوب الشرقي، إلى الريف، واذا كان استعماله عند بعض القبائل يتخد صيغة المؤنث تغرمت ويطلق حينئذ على لئى

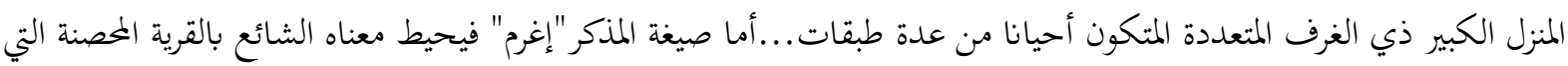

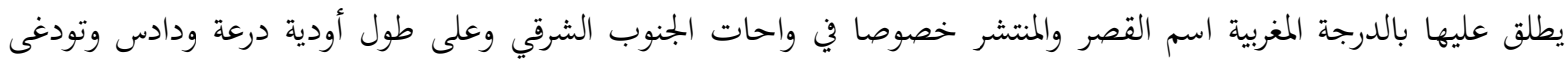

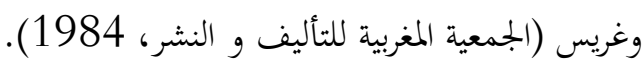

القصر أو "إغْرْم" حسب تعبير الباحث محمد لمراني علوي(كلية الآداب مكناس) هو خلية سكنية تضم العديد من المنازل

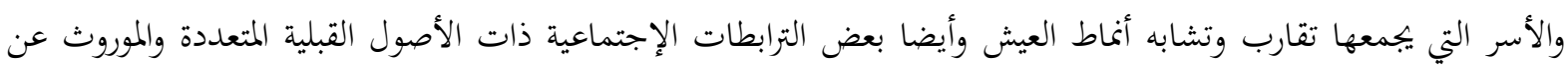

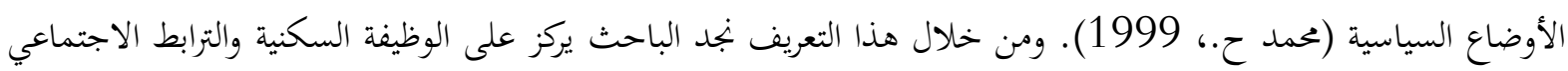
للقصور.

ما يمكن أن نخلص اليه في الأخير أن المعمار الطيني عبارة عن بنايات تقليدية أنتجتها الظروف التاريخية،المناخية و الأمنية؛

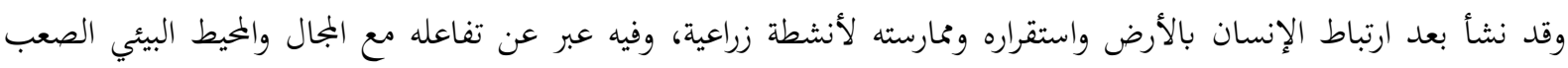

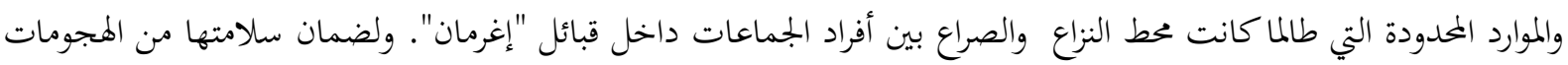

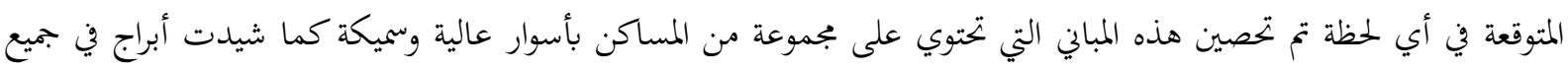

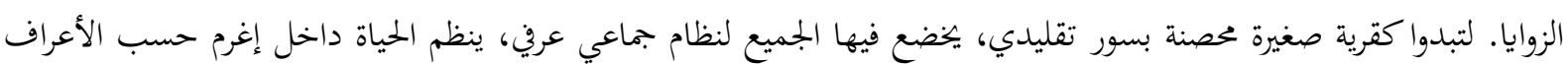
المتفق حولها.

القصبات: ويطلق عليها باللغة المحلية إسم "تِغْْْمَتِنْ". لمُ يأتي بناء" تغرماتين "بشكل اعتباطي، انما أسهم في ذلك ظروف

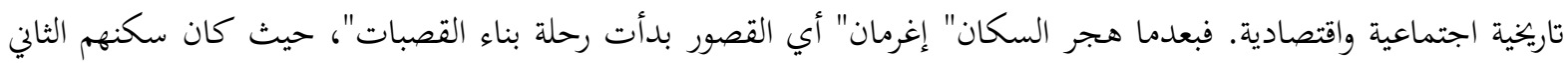

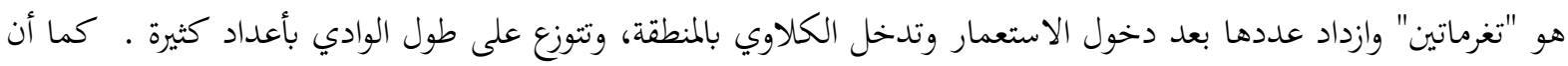

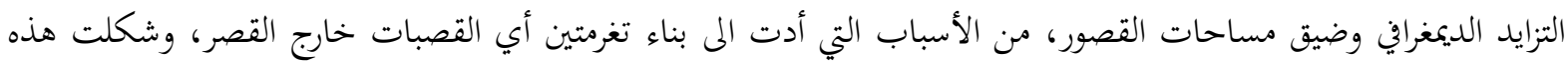
المرحلة أولى البوادر والإشارات

لاحتضار إغرمان بعد اهمالها بالكامل. و تِغْرْمْتُ أو القصبة لا تختلف كثيرا عن المباني التي نجدها داخل القصور. وانما ما

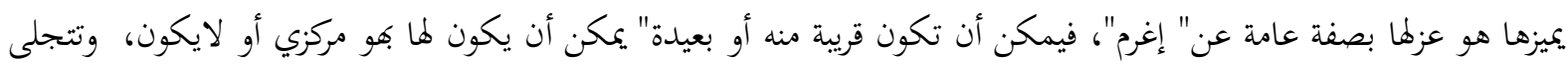

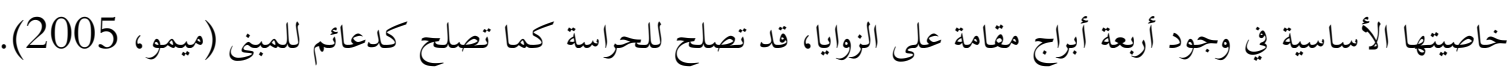

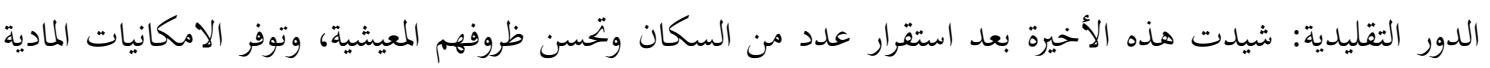

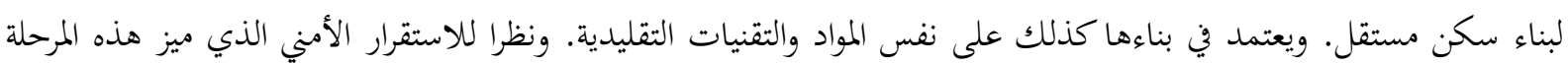
التي شيدت فيها إنعكس ذلك على شكل البناية، حيث يلاحظ غياب الأبراج التي كانت تستعمل للمراقبة وذلك لإستباب

3 بتحهل الكثير من الباحثين التسمية الأصلية والفعلية لهذا المعمار حيث يقدمه الكثيرين على تسمية القصر بمعنى" إغرم "والقصبة بمعنى"تغرمت" والأجدى هو

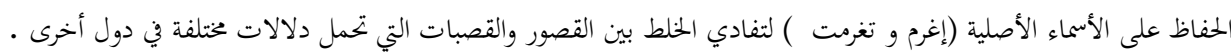


تطورت هذه المباني على مر التاريخ من إغرمان الى تغرمتين الى دور تقليدية، وتتميز بخصائص مناخية متميزة حيث تلطف

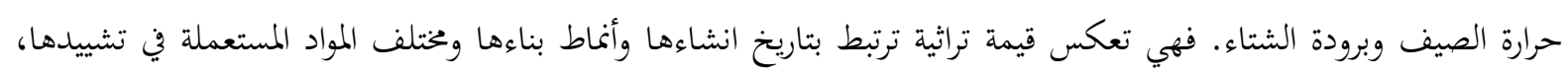
وعلاقتها بشخصيات وأحداث تاريخية.

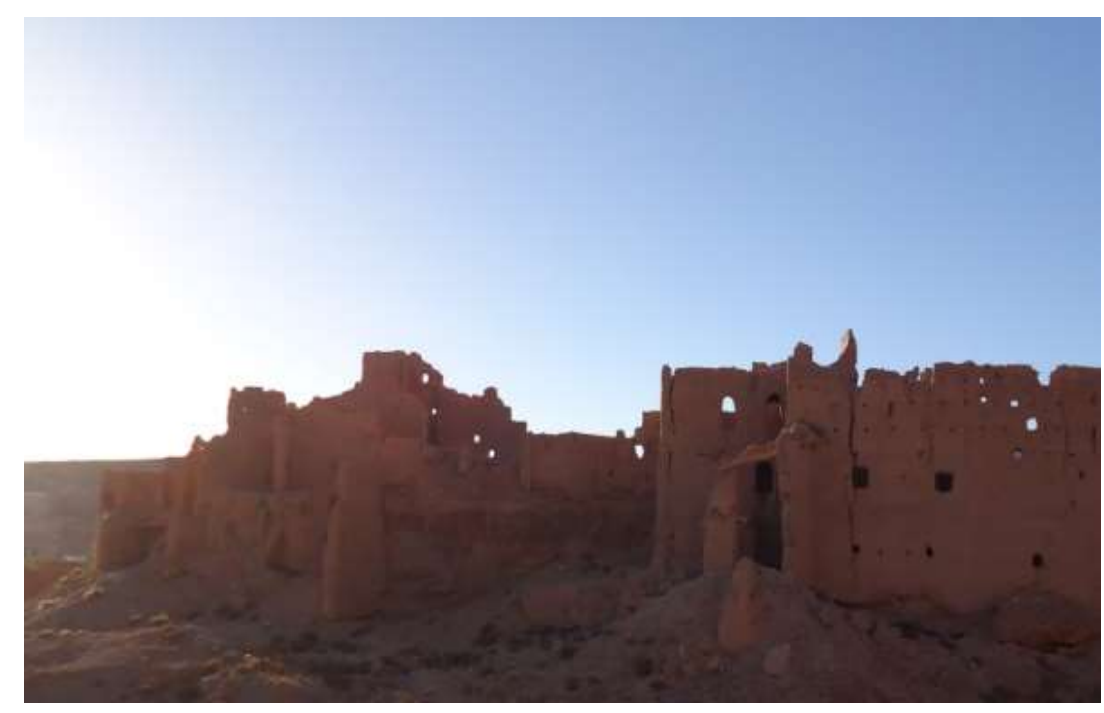

صورة رقم 1: نموذج للقصر بدوار أقبوب

المصدر: تصوير شخصي، 2014

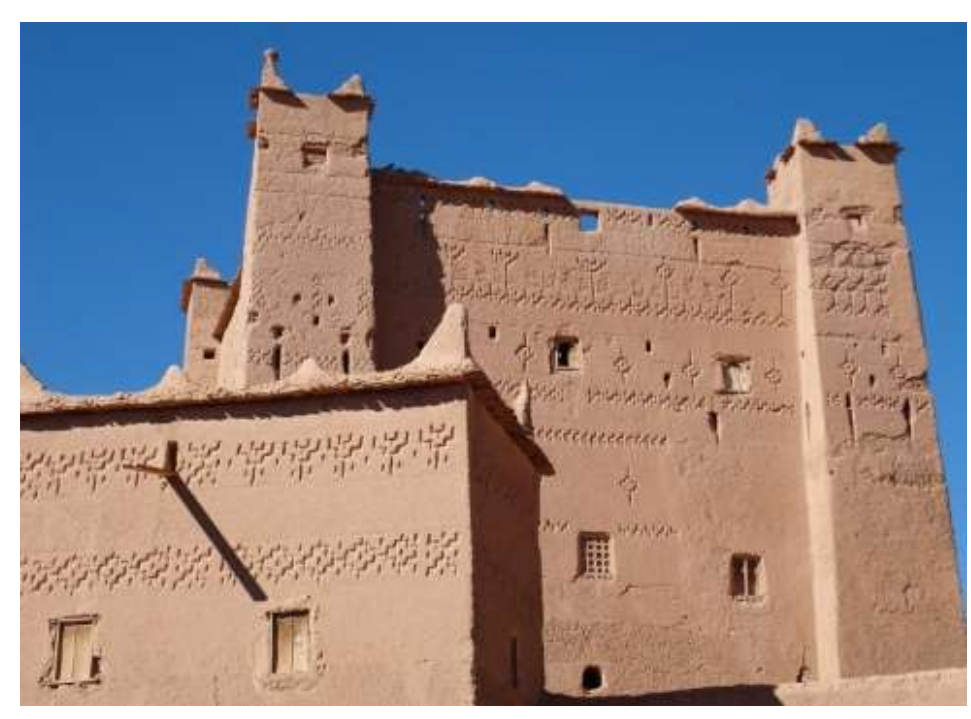

صورة رقم 2: نموذج للقصر بدوار أيت بومان

المصدر: تصوير شخصي، 2014 فوذج للفر بلور ابت بومان 


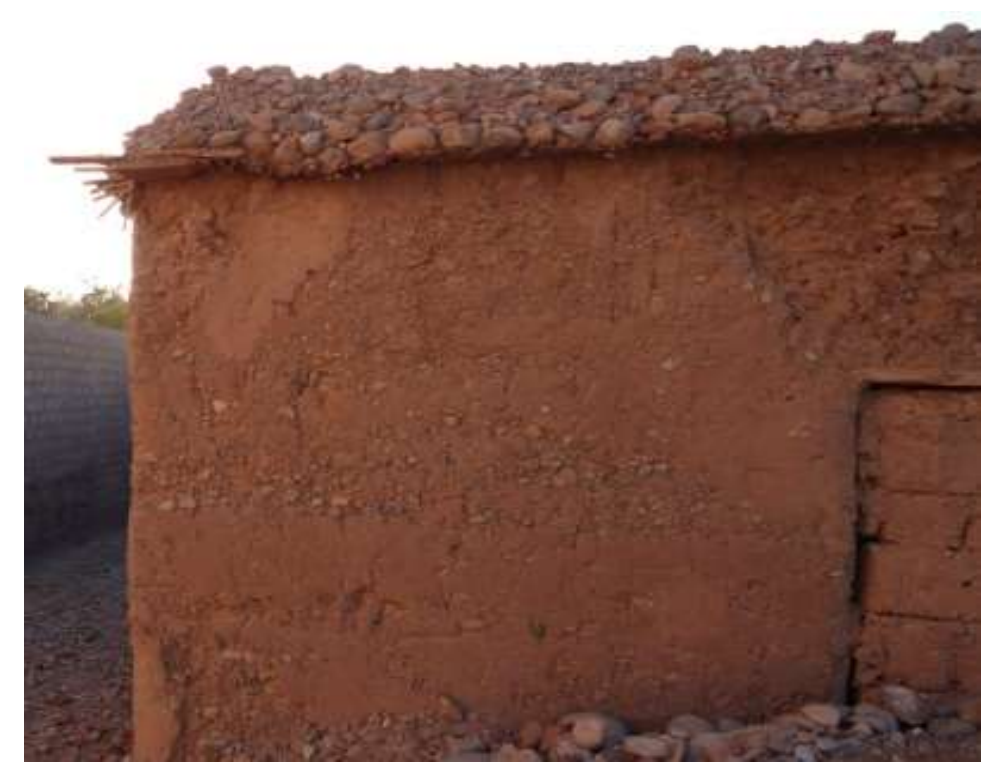

صورة رقم 3: نموذج للقصر بدوار أيت عبدون المصدر: تصوير شخصي، 2014

توضح الصور التالية، مجموعة مختلفة من المباني الواحية التقليدية. شيدت في مراحل تاريخية مختلفة، بناء على الأوضاع الاقتصادية والاجتماعية والسياسية التي تميز كل مرحلة.

2. المزايا البيئية للعمارة الواحية التقليدية

تتضح المزايا البيئية داخل مباني الواحة التقليدية في جوانب مختلفة. تنطلق من الكفاءة العالية في تدفئة الهواء الداخي للبناية

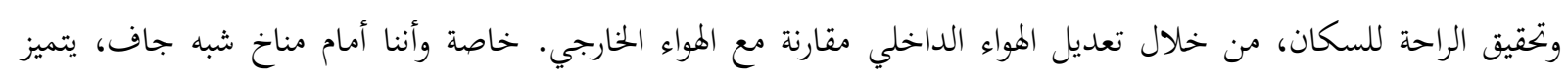

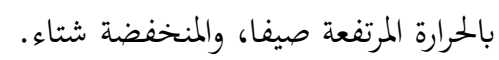

نجد الملائمة البيئية في العمارة الواحية على مستوى مواد البناء المستعملة وكذا على مستوى التقنيات. هذا الشكل العمراني المتوارث عبر الأجيال تم تشييده تلقائيا مع مراعاة الظروف المحيطة بالسكان أنذلك منها؛ الأمنية، والاقتصادية والطبيعية.

1.2

اعتمد الإنسان بواحة دادس على ما توفره البيئة الطبيعية من مواد أولية لتشييد المباني، واستعمل التربة والخشب والتبن وجذوع الأشجار المحلية والقصب. حيث لم يتطلب البناء منه السفر البعيد والبحث عن الجلديد انما، يستخدم ما توفره له بيئته

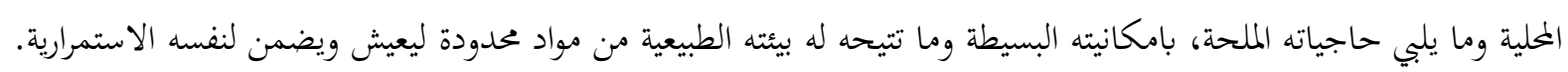

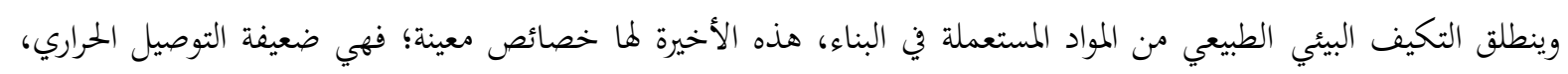

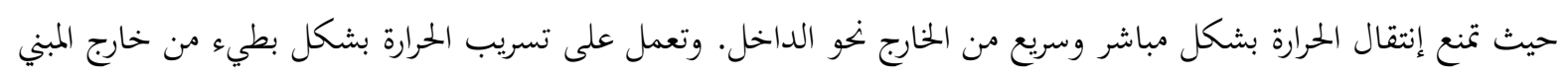

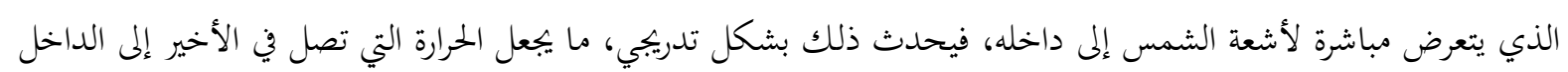




\section{2 التكيف البيئي بين تقنيات البناء وشكل البناية}

يتناسب هذا النوع من العمارة في مواجهة الظروف المناخية القاسية، إنطلاقا من التقنية المستعملة في البناء وشكل البناية.

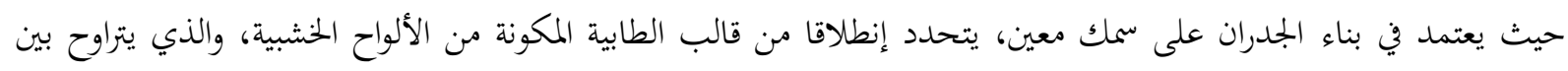

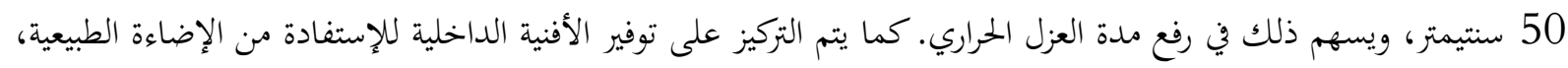
وبتحيد الهواء داخل البناية للحفاظ على مناخ معتدل في الداخل.

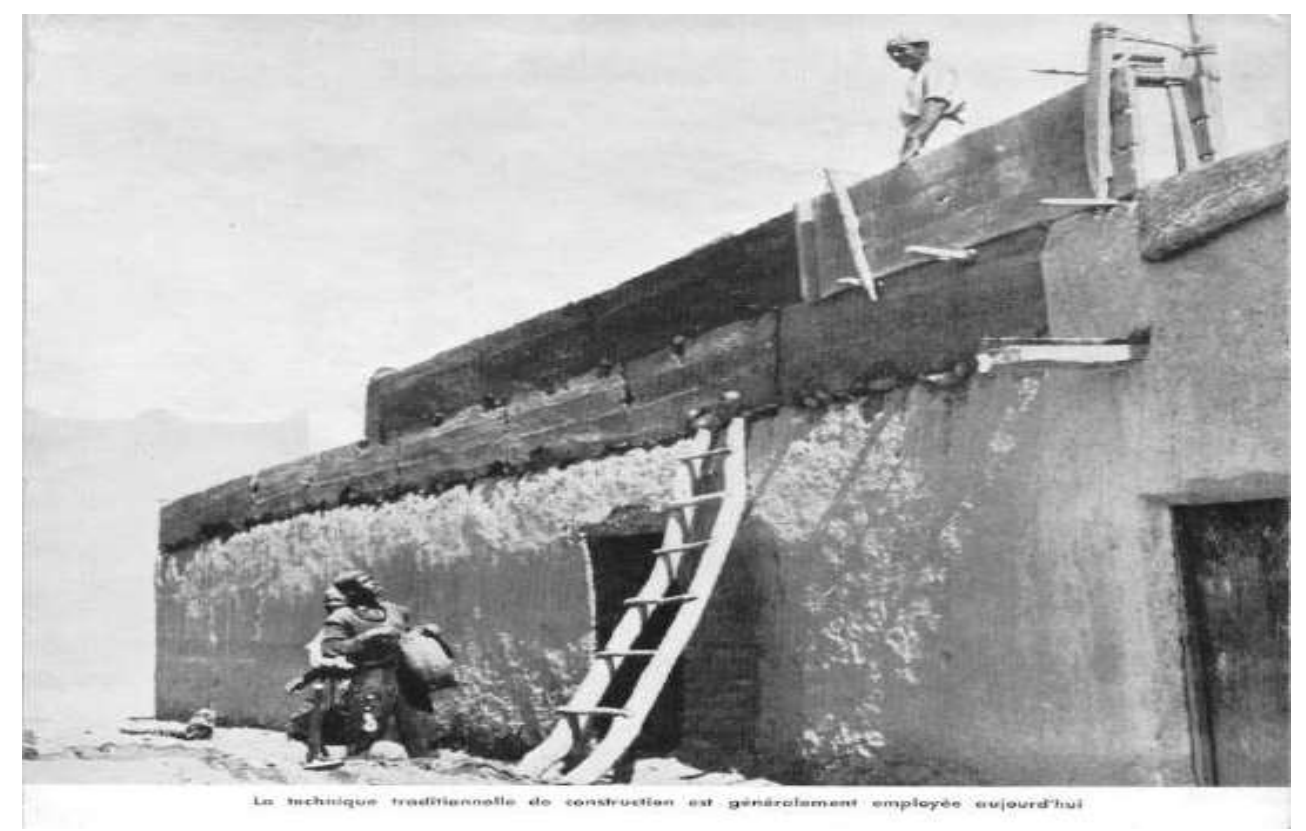

صورة رقم 4: تقنية الطابية أو التابوت المعتمدة في بناء العمارة البيئية

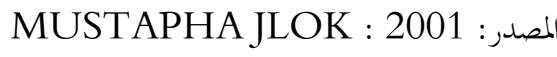

إن هذه البنايات بمزاياها المتعددة وخصوصياتا المحلية، تعرضت للإهمال، بعد التحولات المجالية التوسع العمراني الحديث

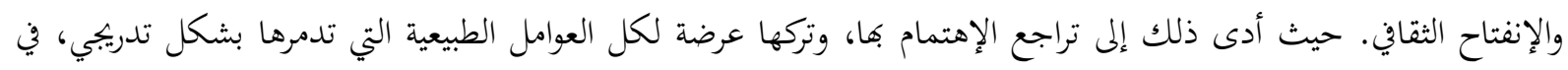
ظل غياب عملية الترميم.

\section{3. تأثير العوامل الطبيعية على العمارة البيئية}

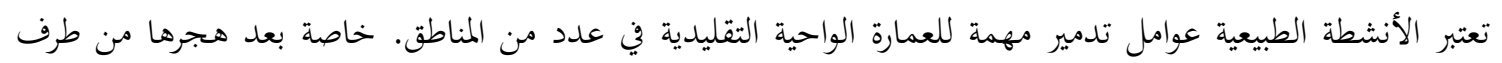

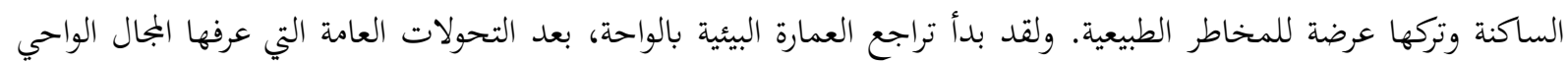

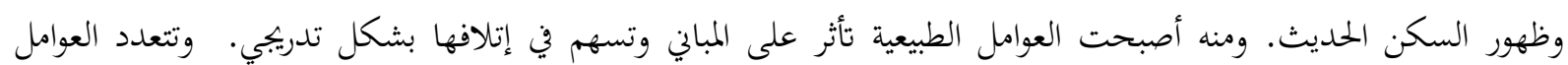
الطبيعية المؤثرة على العمارة البيئة؛منها ماهو ميكانيكي وفيزئيائي.

1.3.

تأتي أهمية الإشارة إلى الوضعية المناخية داخل الواحة إلى أهمية الخروج بمعطيات موضحة للسمات الأساسية المميزة للمناخ الواحي،

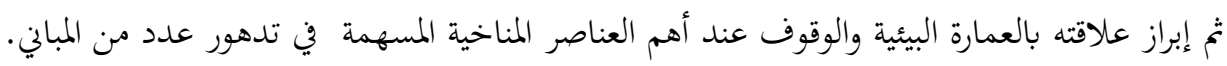

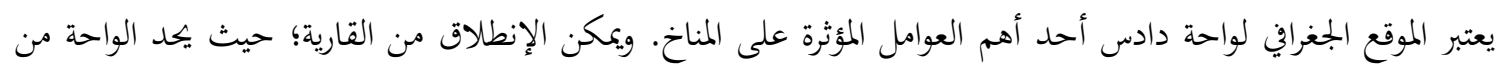

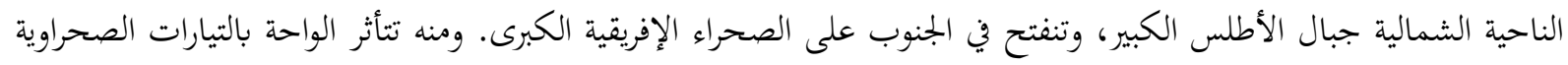

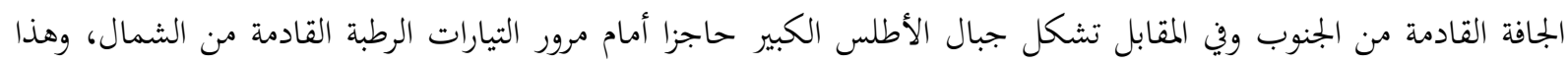


"يجعل مناخ الواحة يتميز بالقساوة. ويتضح ذلك من خلال التفاوت الكبير في درجة الحرارة، وشح الأمطار المتساقطة وتباينها.

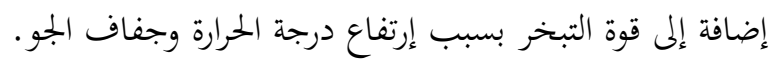

$$
\text { تأثير التساقطات المطرية }
$$

على الرغم من قلة الأمطار لسيادة المناخ شبه الجاف، إلا أنه تشهد أحيانا بعض السنوات المطيرة، ذات أمطار غزيرة

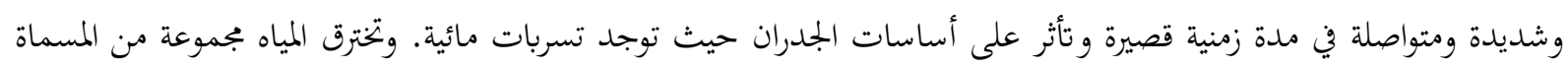

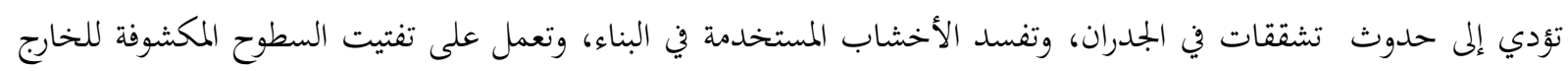
خاصة إذا تراكمت المياه بعد إنسداد قنوات التصريف. إن التساقطات المطرية من ضمن الأسباب الرئيسية التي أدت إلى تدهور

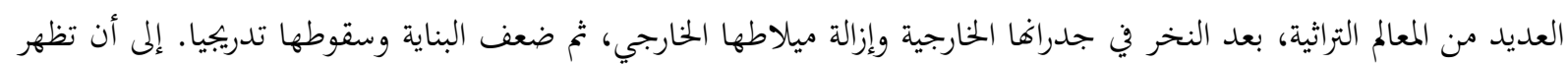
معالمها الداخلية التي لا تسلم هي الأخرى من مجمل هذه التأثيرات.

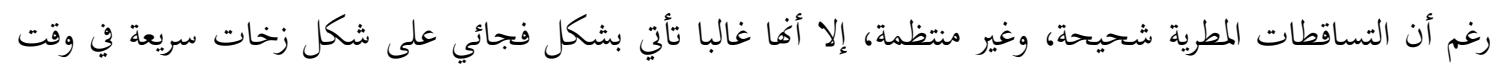

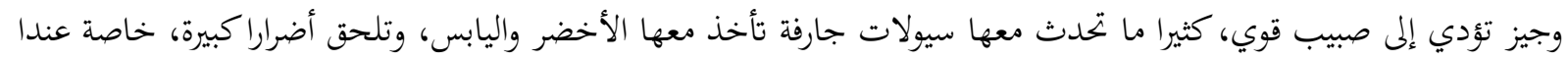

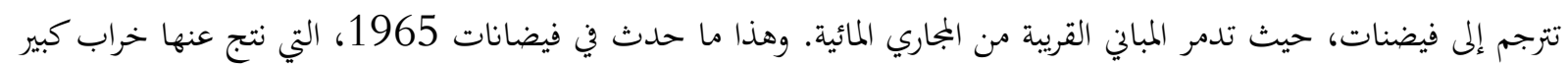
للعمارة البيئية وزوال عدد مع هذه المباني. صورة رقم 6: نموذج للقصر بدوار أيت عبدون صورة رقم 5: نموذج للقصر بدوار إمزيلن

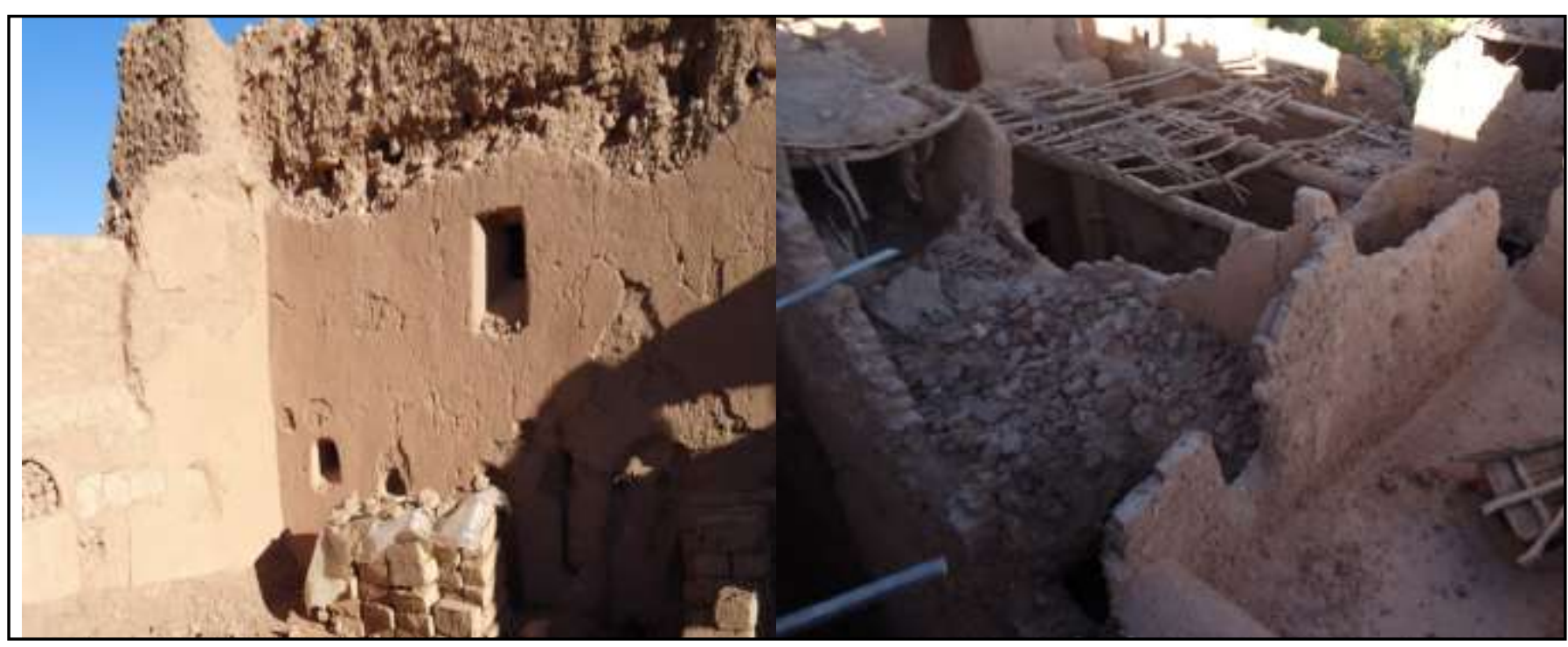

المصدر: تصوير شخصي، 2014

المصدر: تصوير شخصي، 2014

رغم أن التساقطات المطرية شحيحة، وغير منتظمة، إلا أغا غالبا تأتي على شكل زخات مطرية سريعة في وقت وجيز.

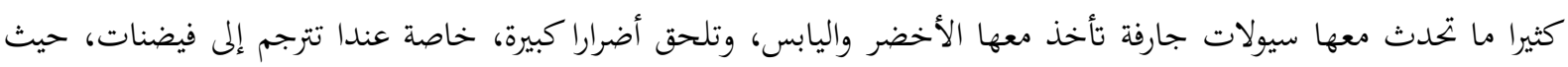

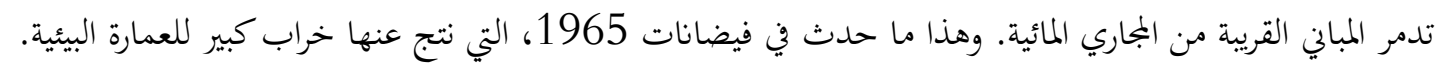


صور جوية: توزيع العمارة البيئية بواحة دادس

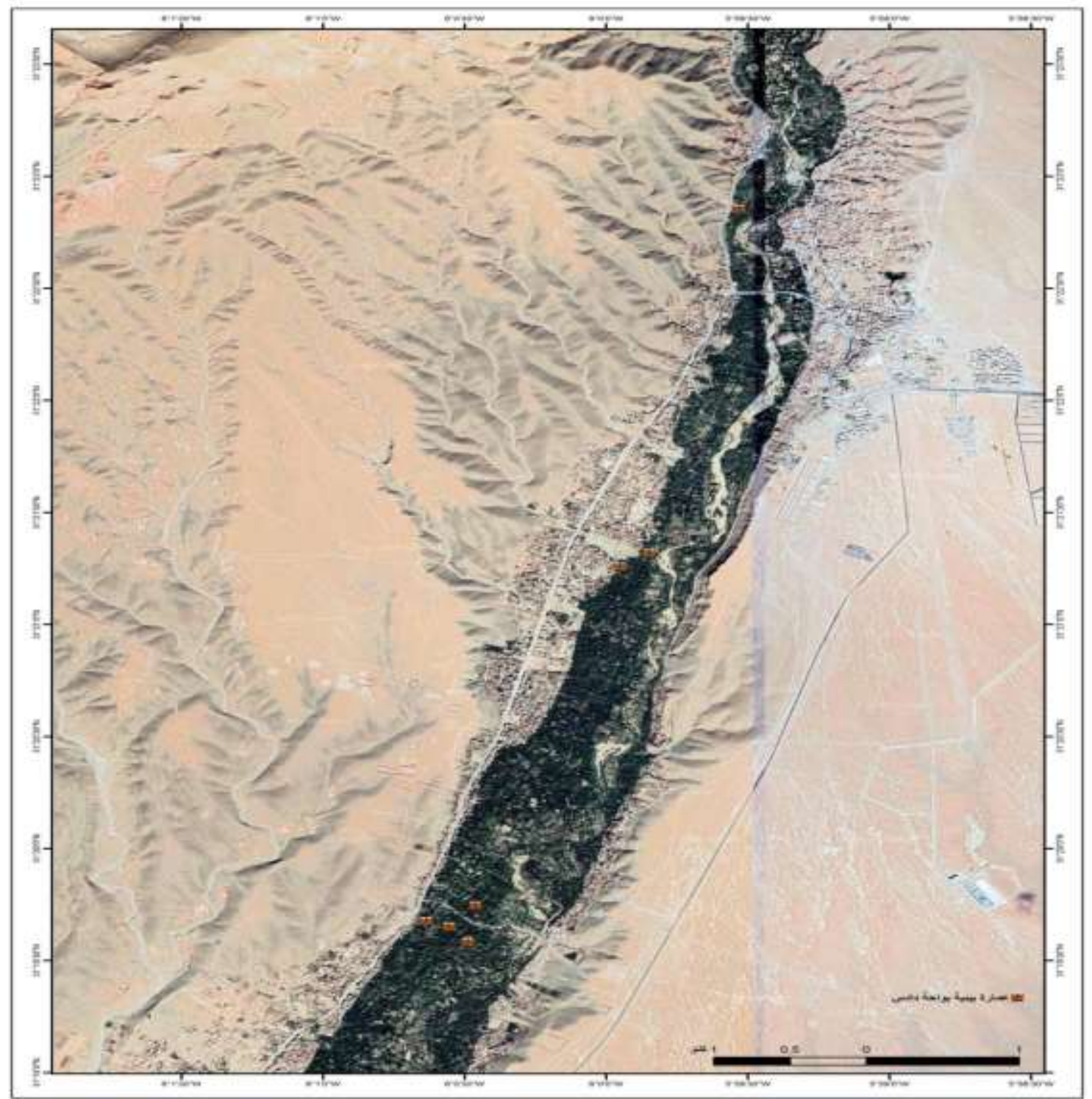

Google Earth المصدر: برنامج

3.3 تدخل عامل الرطوبة في إضعاف العمارة البيئية

تتعرض العمارة البيئية لمشكل الرطوبة بشكل كبير. وتظهر هذه الخطورة عند البنايات التي تتوسط الحقول الزراعية، وقريبة من المجاري المائية. تتسرب المياه إلى الجدران عن طريق المسامات وتؤثر على البناية إنطالاقا من:

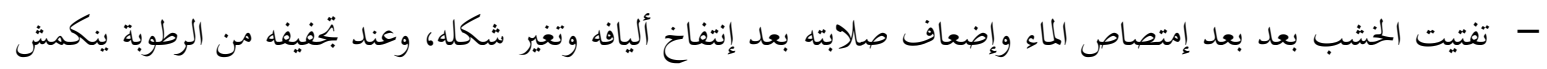

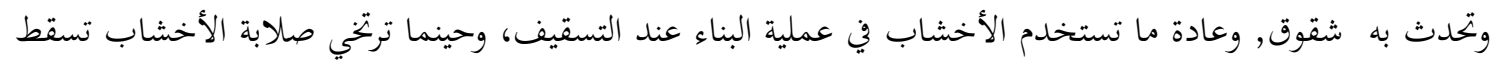
الأسقف؛

- نمو بعض النباتات ولو بشكل ضعيف، بحكم أن الواحة تعرف مناخا جافا تغيب في الرطوبة. إلا أن الرطوبة التي تؤدي إلى نمو النباتات ناتحة عن الأمطار المتساقطة والضايات النابتحة عنها بسبب تراكم المياه في الأجزاء السفلية من الجدران.

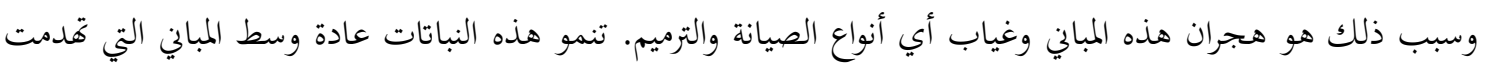

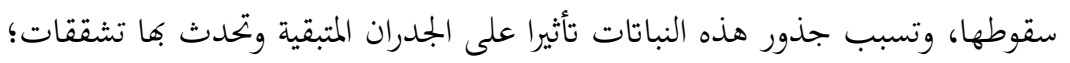


- - إمهان مواجهة الطبقة الخارجية وسقوطها، بعد تعرضها لعمليات تدهور ميكانيكية وفيزيائية. - فقدان أساسات البنايات للصلابة بعد بتع المياه بالقرب من الأساسات واختراق المياه للمسامات، كما يصبح اللحام

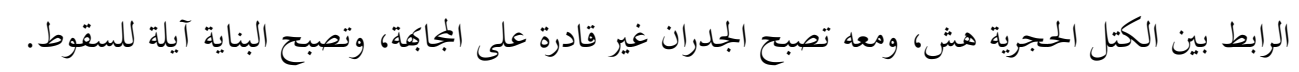

مصدر الرطوبة بالنسبة للعمارة الواحية نابع بالأساس من القرب من المصادر المائية. حيث أن أغلبها يتموقع بالقرب من وادي دادس.

ثم مياه الأمطار المؤثرة بشكل وتأثر الرطوبة على المبنى إنطلاقا من؛ تفتيت الخشب المستخدم في البناء تدريجيا، وتكاثر الفطريات والبكتيريا في المبنى، وتساقط ميلاط الجدران. وتتعرض المباني المجاورة لوادي دادس لرطوبة كبيرة تأثر على أساس البناية. حيث تأثر على أساس البناية. تتسرب المياه إلى

الجدران عن طريق المسمات.

\section{3 فعالية الرياح الجنوبية والجنوبية الشرقية}

تدخل الرياح ضمن العوامل الميكانيكية المؤثرة في العمارة البيئية، وهذه الأخيرة بكل كبير في تدهور عدد من المباني.

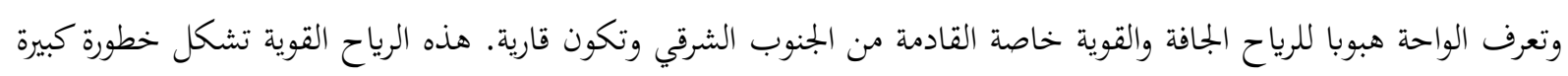

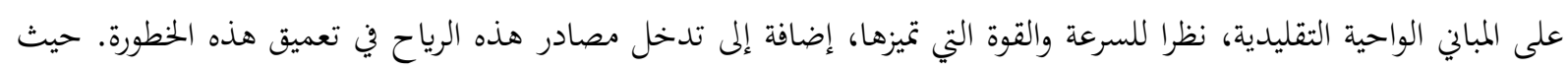
الواحة تستقبل الواحة في الغالب الرياح القادمة المناطق الصحراوية الجافة.

عادة ما تكون هذه الرياح محملة بالحبات الرملية الخشنة والصلبة. وبعد إصطدام الرياح المحملة بالرمال بالجدران الخارجية

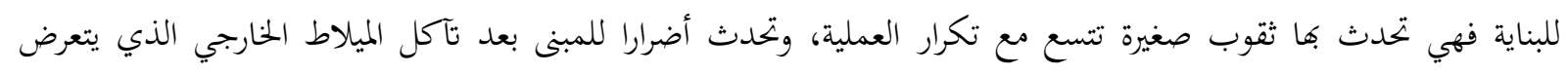

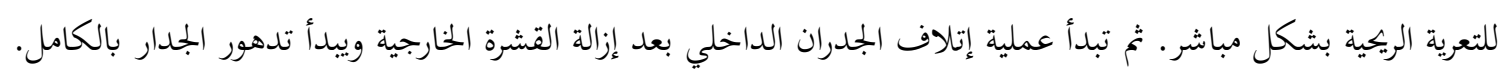

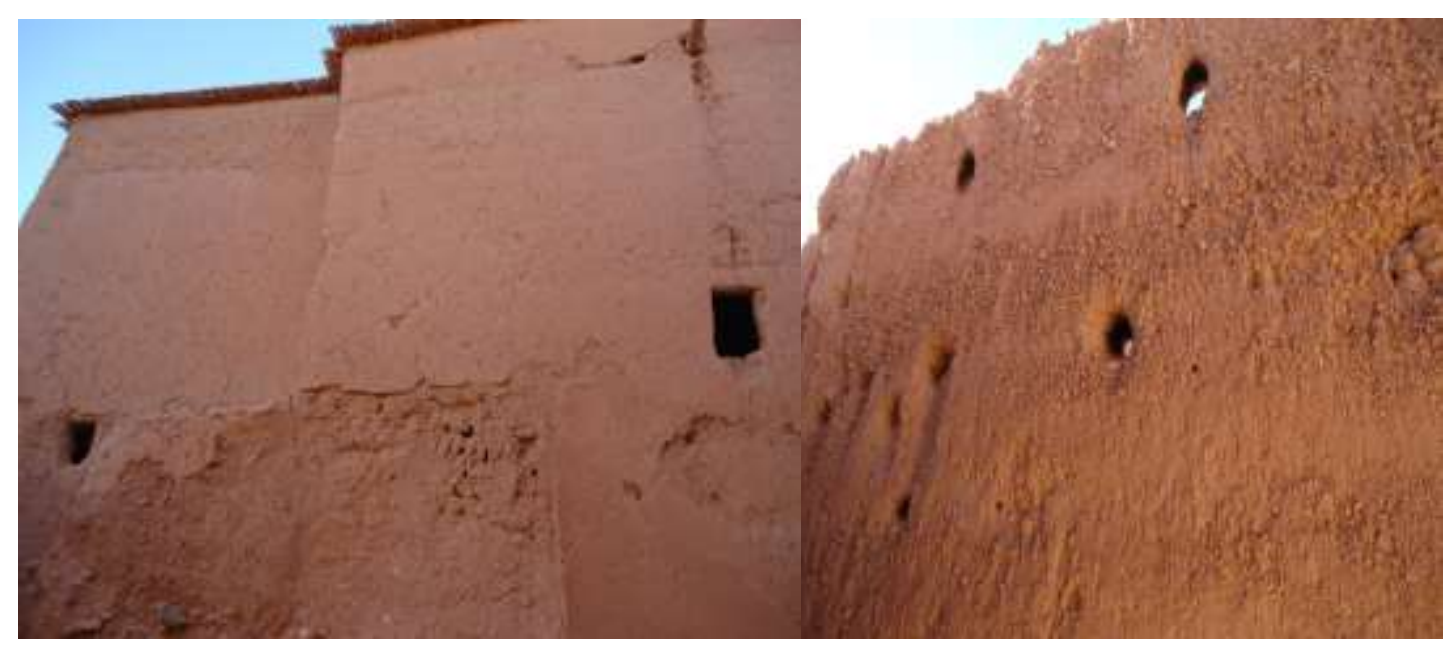

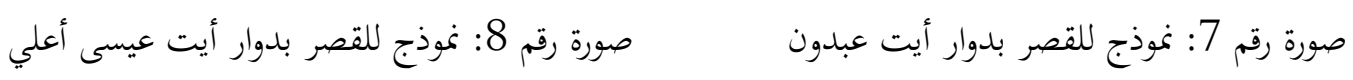

$$
\begin{aligned}
& \text { المصدر: تصوير شخصي، } 2014 \\
& \text { المصدر: تصوير شخصي، } 2014
\end{aligned}
$$




\section{3}

تدخل الحرارة ضمن العوامل الفيزيائية المؤثرة في العمارة البيئية، نتيجة التفاوت الكبير في درجة الحرارة بين السنوات، وبين

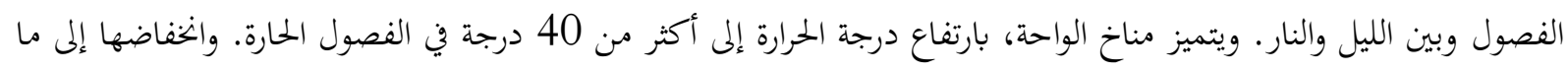
دون الصفر في الفصول الباردة. حيث قد يصل أدنى معدل مسجل إلى (9-) درجات. والعوامل المتحكمة في حرارة المنطقة متنوعة، تتلخص في القارية والإرتفاع والعرض، وهي عوامل حاسمة يضاف إليها التوجيه، و تأثيره محلي مادام التوجيه السائد هنا

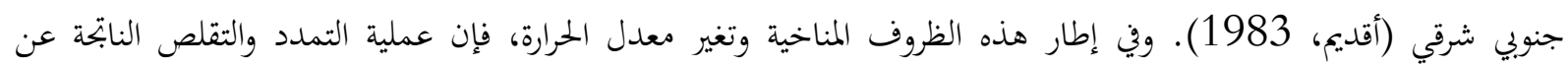
الإختلاف في درجة الحرارة تتردد باستمرار سواء بين السنوات أو الفصول أو بين الليل والنهار.

الحرارة المرتفعة: تتأثر المواد المشكلة للبناية بارتفاع درجة الحرارة. وتؤدي إلى تمددها بعد زيادة حجمها. لأن هذه المواد بعد تعرضها للتسخين بفعل أشعة الشمس تتمدد عند كل الاتحاهات وتتغير حالتها. رغم أن التمدد يبقى نسبي، إلا أنه يظهر تأثيره

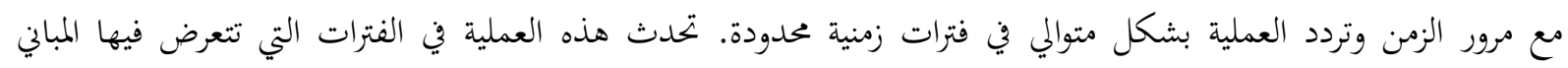

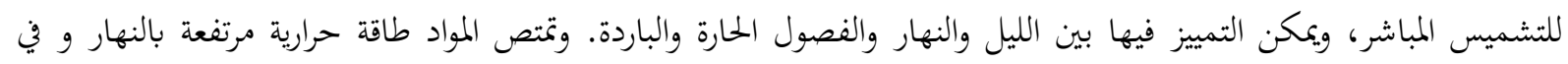

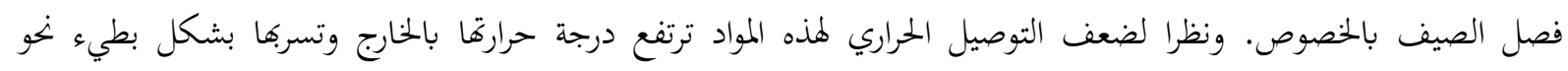

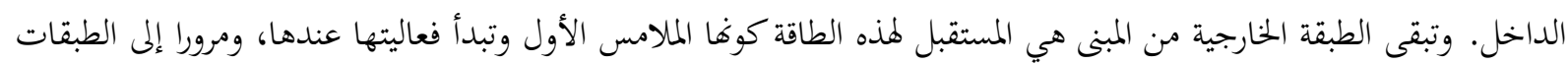

الحرارة المنخفضة: تتعرض مواد البناء إلى تغير في حالتها من جديد بعد انخفاض درجة الحرارة، وتصبح باردة إستجابة

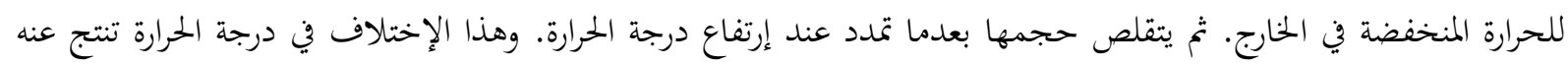

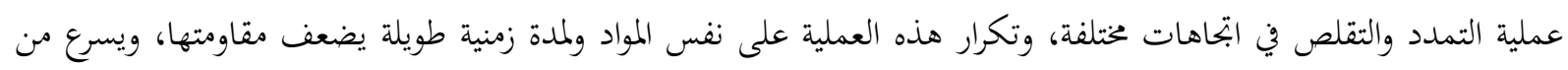

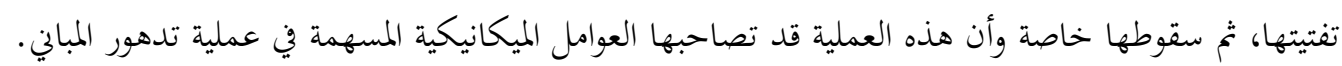
تتأثر الجدران الخارجية للعمارة البيئية بشكل كبير من هذه العملية، خاصة الميلاط الخارجي للبناية. كون هذا الأخير هو هوليه

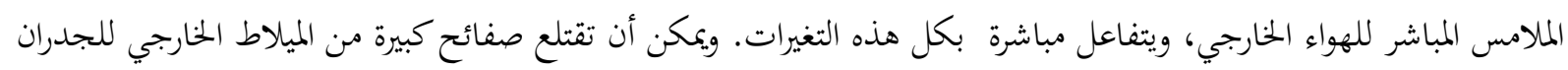
بعد إزالة الحماية ويتسبب ذلك في إتلافه بسرعة. يتدخل الماء المتسرب إلى الجدران عبر المسامات في إحداث أضرار على مستوى العمارة البيئية، بعد تغير حالته الفيزيائية

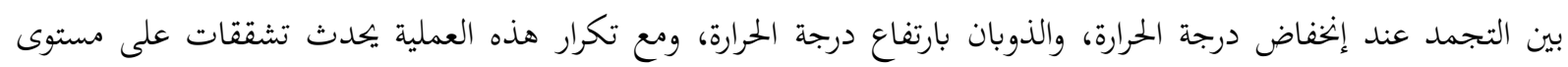

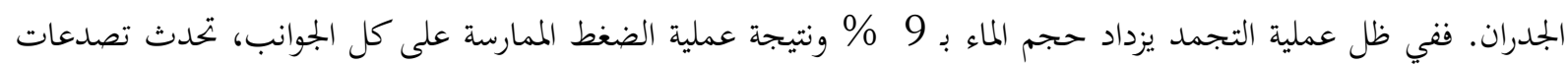
تتسع مع تكرار هذه العملية، كما تتفتت المواد المشكلة للبناية ثم سقوطها تدريجيا. 


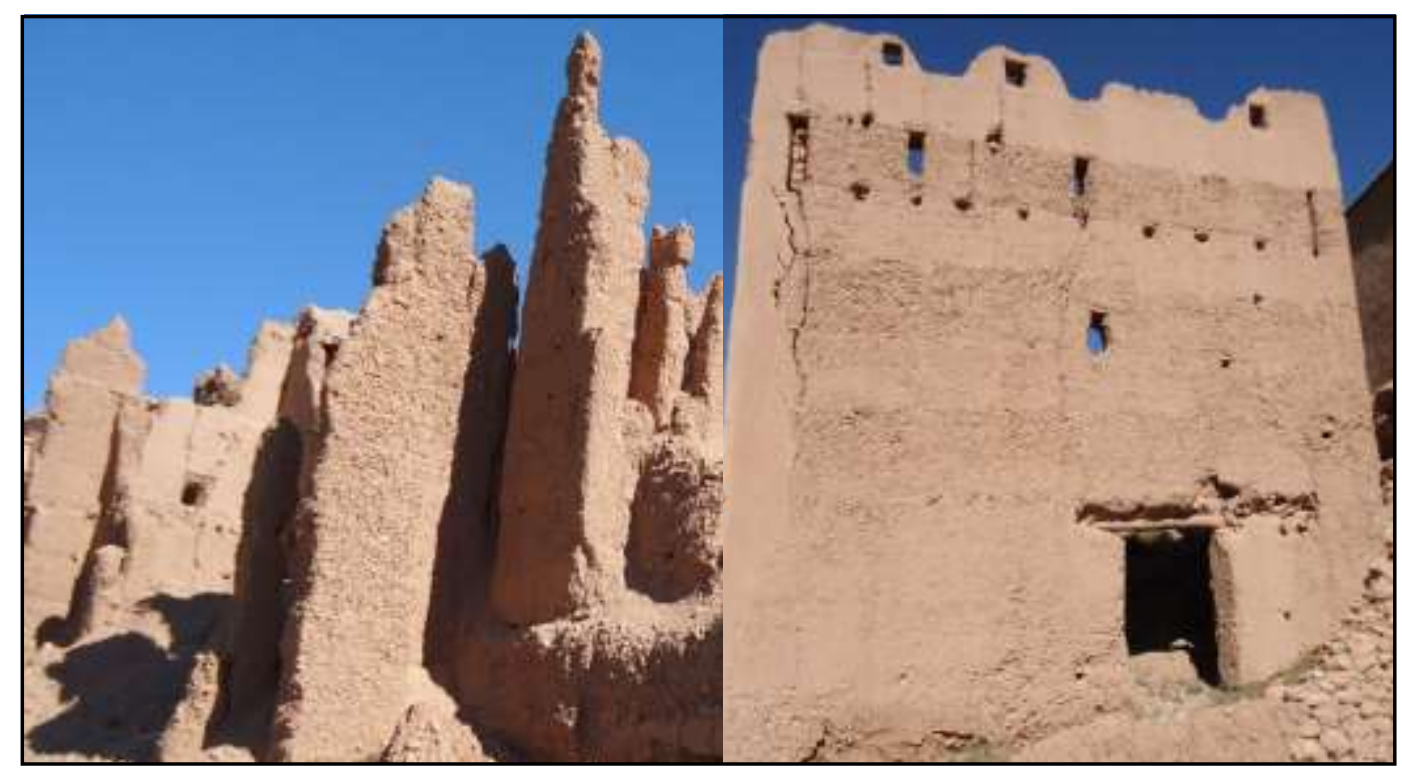

$$
\begin{aligned}
& \text { صورة رقم 7: نموذج للقصر بدوار أيت عبدون صورة رقم 7: نموذج للقصر بدوار أيت عبدون } \\
& \text { المصدر: تصوير شخصي، } 2014 \text { م } 2014
\end{aligned}
$$

إن هذه الأخطار الطبيعية تبدوا تأثيراتا بشكل جلي، ويمكننا توقع الأسوأ مسقبلا، ما لم نعي هذذه الأخطار وأثارها

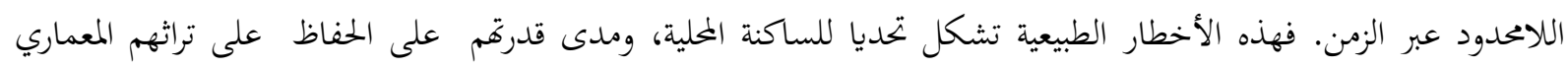

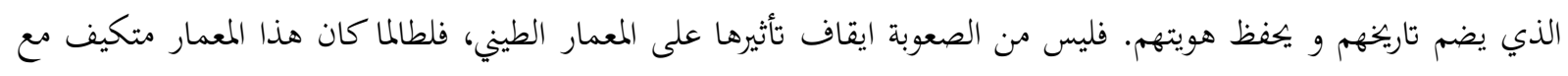

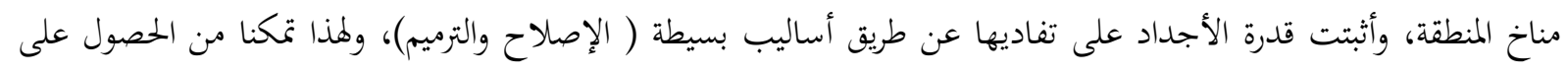
معمار طيني متكيف مع الظروف المناخية.

مع فقدان الأفكار المسايرة للاستمرارية، بدأنا نفقد هذه المعالم بشكل تدريبي. لذلك لابد من الوعي بأهمية البنايات

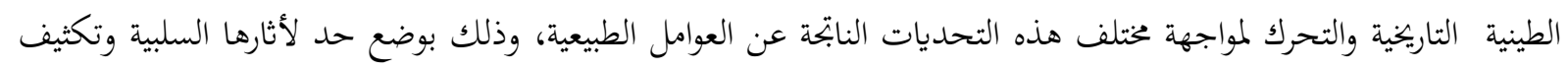

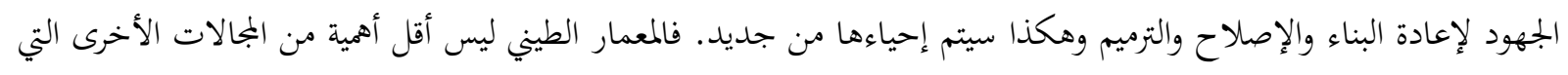

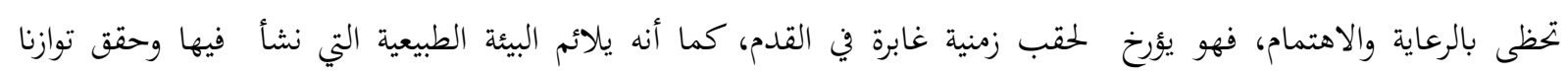

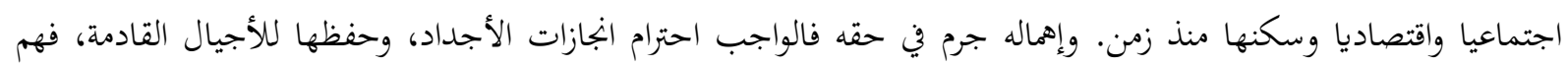

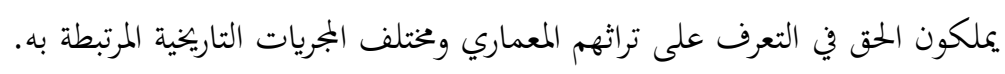


إن مواجهة التحديات الطلبيعية، ورد الإعتبار للعمارة البيئة والحفاظ عليها من الإندثار، أصبح أمرا ضروريا و ملحا،

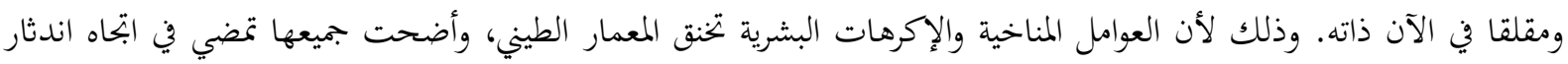
هذا الأخير الذي يشكل موروثا إنسانيا يميز واحة دادس محليا، وسيكون محط جذب مستب مستقبل إذا تم إحياءه وتوظيفه بشكل مستدام. كما أنه يمكن أن يصبح منطلقا لإحياء بجموعة من الفنون الثقافية والأنشطة الحرفية داخل الواحة.

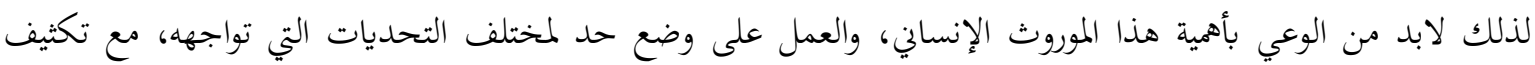
الجهود لإعادة البناء والترميم، و هكذا سيتم احياءه من جديد و و إعادة توظيفه.

\section{من خلال الدراسة تم استخلاص مجموعة من النتائج والتوصيات:}

- أثرت الظروف الاجتماعية التي عرفتها الواحة؛ من تزايد ديمغرافي، الهجرة الخارجية، ظهور خدمات جديدة والإنفتاح على

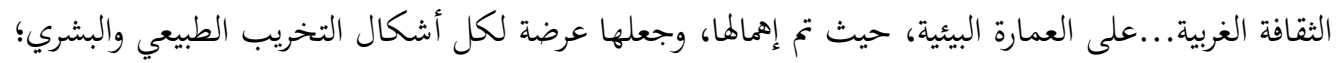
- -

- - هدم مجموعة من المباني التقليدية رغبة في تشييد سكن بموصفات عصرية؛ - - تعدد العوائق على أي تدخل تنموي يخص المعمار الطيني خاصة وأن الوضعية العقارية لهذا الأخير معقدة، إضافة إلى وضعه المتدهور؛ - - غياب المعمار الطيني في مخططات وتصاميم التهيئة العمرانية؛ - - - استمرارية الضغط على العمارة البيئية، أمام التزايد الديمغرافي وحاجة الساكنة لتشييد بنايات اسمنتية حديثة. - - مشكل الملكية الخاصة للمعالم التراثية، ما يصعب كل التدخلات الممكنة.

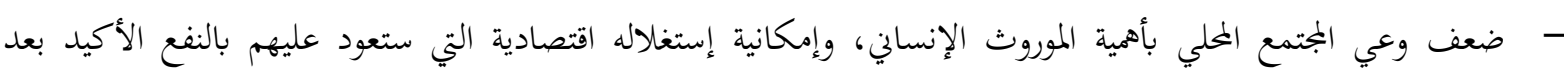
الإسهام في عملية تطويره؛

\section{التوصيات:}

إن طبيعة التحديات التي تواجهها العمارة البيئية بواحة دادس تفرض تكثيف الجهود والمشاركة من أجل رفع مختلف

$$
\text { التحديات الطبيعية، التي تسهم في تدهورها من خلال: }
$$

- - جمع المعلومات والمعطيات الكافية عن العمارة البيئية بالمنطقة لتسهيل عمليات التدخل التنموي وذلك للقيام بدراسات و أبحاث عميقة؛

- - التنسيق بين المتدخلين من؛ الملاكك والدولة ةالقطاع الخاص والمجتمع المدني لرفع قيمة المعالم التراثية وإعادة احياء زمنها المنسي؛

- الحفاظ على العمارة البيئية وإحيائها من جديد، وضمان إستدامتها على المدى البعيد، فهي موروث إنساني لن يكررها

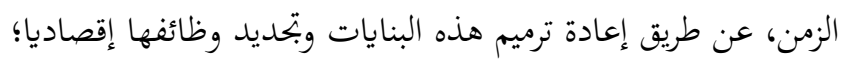


- - إدماج العمارة البيئية في خخططات و تصاميم التهيئة لتأخذ صبغة قانونية وتكون عملية التنمية أمر ملح وضروري؛ - - نشر التوعية بالأهمية البيئية والتاريخية والاجتماعية والاقتصادية للعمارة البيئية وإمكانية إعادة إستغلالها بشكل يضمن إستدامتها؛

$$
\text { - - تصنيف العمارة البيئية كتراث وطني. }
$$

أسهمت هذه الدراسة في تبيان بعض من التحديات الطبيعية التي تواجهها العمارة البيئية داخل المجال الواحي لدادس. في حين أن جوانب أخرى من العوامل المدمرة لا تزال خفية، تحتاج إلى دراسات أخرى تنفض الغبار عنها وتكشفها للواقع، لتسهيل عمليات التدخل لإعادة إحياء هذا الموروث الإنساني الذي هجر لسنوات وترك عرضة للضياع. وذلك لتسهيل كل عملية تدخل تروم إعادة الإحياء من جديد، بطرق تضمن إستدامته على المدى البعيد. 
ابراهيم أقديم. (1983). إسهام في الدراسة الهيدرولوجية والمرفلوجية لحوضي دادس وتودغة، بحث لنيل شهادة

$$
\text { الدراسات العليا. الرباط: جامعة محمد الخامس كلية الآداب والعلوم الإنسانية. }
$$

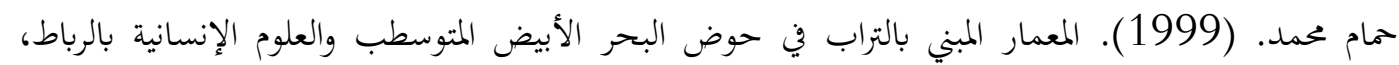

سلسلة ندوات ومناظرات، جامعة محمد الخامس، ص101. 101. (المجلد الأولى). الرباط: كلية الآداب والعلوم الإنسانية.

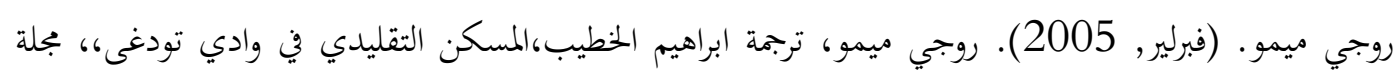

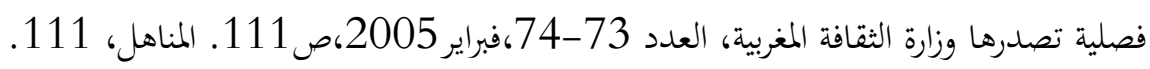

DE FOUCAULD C., 1888, Reconnaissance au Maroc, Société d'Edition

Géographique, Maritimes et Coloniales, Paris, 493.

JACQUES MEUNIE., 1963, Architectures et Habitats du Dadès, Journal de la société des Africanistes.

MUSTAPHA JLOK., 2001, Habitat et Patrimoine au Maroc Présaharien, Etat des lieux, Evolution et Perspectives de Développements, cas D’IGHREM N IGOULMIMN, Mémoire de Fin d'Etudes, Université internationale en langue Français au service du développement Africain Département Gestion du patrimoine culturel.

https://srtm.csi.cgiar.org/index.asp 